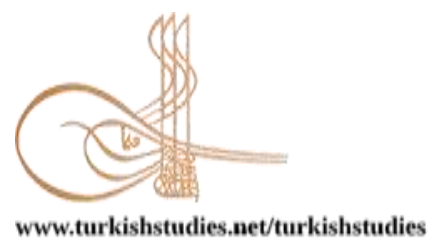

Turkish Studies

\title{
Covid-19 Sonrası Kent Planlamasında Yaşanacak Olası Değişimler Üzerine
}

On Possible Changes in Urban Planning After Covid-19

\author{
Damla Balcı* - Ali Türk ${ }^{* *}$
}

\begin{abstract}
This article research; at the beginning of the spring months of 2020, while the Covid-19 pandemic affecting the whole world and Turkey was experienced, the urban planning of the changes of urban residents for urban uses was prepared with the aim of questioning the discipline. Within this framework, thoughts are expressed on the effects and possible consequences of Covid-19 epidemic on urban living spaces and the habits of urban residents. "Potential" changes are listed as much as possible, considering that the process of the epidemic is long and is involved in a stage that is not yet visible. This article research prepared in the process of dealing with a pandemic crisis in the World countries and Turkey, instead of a large source of literature by academic circles in urban planning and other disciplines, it presents an original research study that most of it takes its source from the process. In this context, in the article research, the method of evaluating is based on these changes that will be experienced in urban planning through the eyes of a city person and a city planner in the process. While ranking the possible urban changes to be experienced in the area of urban planning, it has been evaluated on the whole city scale and has been created in a connected way from the whole of urban life. These possible urban changes and urban planning oriented ideas, offer views and suggestions open to renewal. Considering that the results of the process and the progress of urban use have not yet been seen, flexibility or a different alternative is left in the evaluations. The article research reveals that urban planning understanding and operation is always open to change as long as the urban habits change.
\end{abstract}

Structured Abstract: Introduction and Research Purpose: In Turkey confront the epidemic in March in 2020 is given a struggle with the Covid-19 outbreak as in all world cities. Since protecting public health is the main goal in this struggle, policies to reduce the possibility of transmission have been implemented in the cities. Our cities and city dwellers have found themselves in a rapid transformation process with administrative decisions. Thus, a view that changed the flow and empties the streets has emerged in our cities. City planners who planned the cities were caught by focusing on solving a series of technological and fast-paced problems. While our cities drowned in other problems, the flowing life was suddenly stopped. This pause initiated the emergence of questions in the minds of the citizens and efforts to include urban life

\footnotetext{
* YL Öğrencisi, Süleyman Demirel Üniversitesi, Mimarlık Fakültesi, Şehir ve Bölge Planlama Bölümü Master Student, Süleyman Demirel University, Fakulty of Architecture, Department of City and Regional Planning ORCiD 0000-0003-3693-5601

dbalci29@outlook.com

*** Prof. Dr., Süleyman Demirel Üniversitesi, Mimarlık Fakültesi, Şehir ve Bölge Planlama Bölümü Prof.Dr., Süleyman Demirel University, Fakulty of Architecture, Department of City and Regional Planning ORCID 0000-0002-9934-0915

aliturk@sdu.edu.tr

Cite as/ Atıf: Balc1, D. \& Türk A. (2020). Covid-19 sonrası kent planlamasında yaşanacak olası değişimler üzerine. Turkish Studies, 15(8), 3389-3400. https://dx.doi.org/10.7827/TurkishStudies.45905

Received/Geliș: 23 August/Ağustos 2020

Accepted/Kabul: 20 December/Aralık 2020

Copyright $($ ) MDE, Turkey
} 
in their homes in this order. In the planning discipline, solution arrows are tried to be drawn first for the city dwellers, and then for the city. Inquiries about the new urban order that the pandemic process will create as a result of the persistence or the result of this rapid transformation on the cities have begun. In academic circles, the writing process has been made in the name of Covid-19 and urbanism. However, considering that the epidemic has not ended while it is still in the process, it is useful to give opinions that are more general and open to continuous renewal. In this period when the process is trying to be carried out from all areas and risk management is essential, any definitive planning provision will remain shallow. This article study also questions the changes that urban residents have experienced in urban planning in the course of the epidemic. As a city dweller and urban planner, it is aimed to reveal the changes and possible consequences of urban life in the Covid-19 outbreak.

\section{Article Abstract and Basic Conclusions}

With the introduction of Covid-19 into our lives, we have had time to observe many changes. At first, the appearance of the cities created different feelings for us all. The new images that emerged in the cities in this process showed once again that the creator of the city is human. Human movements are an integral part of urban life. For this reason, the decrease and changes in human movements both in public spaces and in closed spaces in urban life since the outbreak started may lead to the emergence of new planning principles. Possible changes in the urban planning area are conveyed in detail in the article;

* Population density planning in urban parcels,

* Increase in the amount of open and green areas in the city in accordance with spatial standards,

\# Changes in requests for real estate purchase,

\# Differentiation in working conditions and principles in education and business life, institutional field changes,

* Increase in agricultural areas and reappearance of agricultural cities in urban planning,

\# Changes in standards in street and street planning,

\# Diversity of transportation planning due to differentiation in transportation demands,

* Architectural and areal changes in the fields of socio-cultural reinforcement,

are listed as general titles. Each of these listed changes includes topics that urban planning has touched on to create healthy and livable cities for many years. At this point, no suggestions show a transformation that is difficult to make or turn the city into puzzles. On the contrary, it transfers practices towards correct urban use in the long run. This may perhaps provide an advantage for the importance and value of city planning.

\section{Results}

As we get to know the urban life we experienced before the epidemic and the fact of the epidemic today, what has been experienced has brought us small changes in some areas and big changes in some areas. Urban habits also show gradual changes as the process works gradually. The lifestyle, which is completely isolated from the beginning of the epidemic to the stages of control and in which all habits change, returns to urban life with new regulations with the transition of the epidemic process to normalization. For this reason, after observing the behavior of the city planning until the end of the process, the city planning area will be able to make decisions based on implementation. Because planning plans the city according to the city dweller. As a result, as this process teaches, it does not show any signs of life on any urban part without human movement. Human movements are more effective in shaping cities than many physical factors. If the city dweller changes its urban use, it will draw its direction in urban planning accordingly.

Keywords: city planning, Covid-19, urban changing, healthy environment, urban land use

Öz: Bu makale çalışması; 2020 yılının bahar aylarının başında, tüm Dünya’yı ve Türkiye'yi etkisi altına alan Covid-19 salgını yaşanırken, kentlilerin kentsel kullanımlara yönelik değişimlerinin kent planlaması disiplinince sorgulanması amacı ile hazırlanmıştır. Bu çerçeve içerisinde, Covid-19 salgının kentsel yaşam alanlarında ve kentlilerin alışkanlıklarında yarattığı etkiler ve olası sonuçları üzerine düşünceler aktarılmaktadır. Makale çalışması içerisinde, salgının sürecinin uzun olduğu ve sonu henüz görünmeyen bir 
aşamasında yer alındığı düşünülerek mümkün olduğunca "olası” değişimler sıralanmaktadır. Dünya ülkeleri ve Türkiye'nin pandemi düzeyinde bir kriz ile mücadele ettiği süreçte hazırlanmış olan bu makale çalışması şehir planlama ve diğer disiplinler içerisinde yer alan akademik çevrelerce geniş bir literatür kaynağı yerine, kaynağının büyük bir kısmını sürecin içerisinden alan özgün bir araştırma çalışması örneği sunmaktadır. Bu bağlamda makale çalışmasında, kent planlamanın yaşayacağ 1 bu değişimlerin sürecin içerisinde bir kentli ve bir şehir plancısı gözüyle değerlendirilmesi yöntemi esas alınmaktadır. Kent planlama alanında yaşanacak olası kentsel değişimlerin sıralaması yapılırken tüm kent ölçeğinde değerlendirilmiş ve kentsel yaşamda bütünden gelecek şekilde bağlantılı bir şekilde oluşturulmuştur. Bu olası kentsel değişimler ve kent planlama odaklı fikirler, yenilenmeye açık görüş ve öneriler sunmaktadır. Sürecin sonuçlarının ve kentli kullanımlarının ilerleyişinin henüz görülmediği hesaba katılarak, değerlendirilmelerde esneklik veya farklı bir alternatif bırakılmaktadır. Makale çalışması ile kent planlama anlayış ve işleyişinin kentli alışkanlıkları değiştiği müddetçe her zaman değişime açık olduğu ortaya konmaktadır.

Anahtar Kelimeler: şehir planlama, Covid-19, kentsel değişim, sağlıklı çevre, kentsel alan kullanımı

\section{Giriş}

Kentler ve kent planlama, Şehir Plancıları tarafından 21.yy içerisinde hep afetlerle, doğal süreçlerle ve beşeri güçlerle ele alınmaktadır. Son zamanlarda, teknolojik gelişmelerin, endüstrilerin ve betonlaşmanın kentleri soktuğu kalıplardan yakınılmaktadır. Değiştirmeye, düzeltilmeye çabalanmakta, çözümler üretilmektedir. Planlama disiplinin akademik eğitim düzeylerinden itibaren, sürekli karmaşıklaşan kentlerimizi çözümlemeye, yaşatmaya çalışırken şehir planlama alanında yeni boyutlar, projeler keşfedilmektedir (Ersoy,2005). Planlama eğitiminde verilen derslerin arasına geleceği planlarken kentsel dijitalleşme, kentsel teknoloji gibi modern kavramların ve uygulamaların yoğun olarak sunulduğu içerikler eklenmektedir. Tüm bu hayat koşuşturması içerisinde kentlere verilen zararın ne kadar büyük olduğunu anlatmaya çalışan plancılar bile, bir gün kentlerdeki koşturmalı yaşamdan insanları soyutlayacak bir küresel salgını hiç düşünmemektedir. Evet, küresel ekonomiler, küresel iklim değişiklikleri vb. geniş çaplı düşünülmesi gereken her şey şehir plancıları tarafından düşünülmektedir. Peki, bu durum neden atlanmıştır? Oysa tarihten gelen olaylara bakıldığında şehirler ve nüfus sağlı̆̆ı birbiri ile bağlantılıdır (Webster vd.,2020). Kentlerin planlama ile tanışması ve planlamanın yıllar boyu köklü gelişimlere uğraması da böyle kırılma noktaları ile çok yakın bir biçimde olmuştur. 14.yy'da hıyarcıklı veba; Rönesans'ın kentsel gelişimlerine ilham vermiş, 18. yüzyıl sarı humması ve 19. yüzyıl kolera ve çiçek hastalığı salgınları; geniş bulvarlar, şehir çapında kanalizasyon sistemleri, kapalı su tesisatı ile kentleri baştan yaratmıştır (Lubell,2020). 1800'lü yıllarda sanayi devriminin yol açtığı kırdan kente büyük nüfus hareketleri kent planlamanın tarihsel bir gereksinim olarak ortaya çıkışının ardında yatan gelişme olarak görülürken; bağlı biçimde sürecin neden olduğu yeni nüfus yoğunlaşmasının beraberinde getirdiği altyapı, konut, ulaşım ve çevre sorunlarına karşı devlet ve toplumun hazırlıklı olmayış1, 19.yy boyunca artan biçimde olumsuz etkisini sağl1k alanında tifo, kolera gibi hijyen koşulları ile doğrudan ilişkili olan salgın hastalıkların hızlı artışı ile göstermiştir. Sağlık sorunları işçilerin yaşam süresini kısalttıkça üretim verimsizleşmiş ve işçi konutları gibi çözüm yolları denenmeye başlanmıştır. Fakat burjuvazinin altından kalkamayacağı boyutlara ulaştıkça devletin müdahalesi gelişmiş; kent planlama çalışmaları toplumsal destek ve meşruiyetini böyle bir ortamda kazanmış ve ilk planlama girişimleri de bu dönemde gündeme gelmiştir (Ersoy,2005). Bu durumun geçmişte kalması şehir plancılarının da o kent koşuşturması ve karmaşası içerisinde kaldığını göstermektedir. Ya da bir plancı olarak bilinenlerin, akademik eğitim hayatlarında kent planlamaya giriş derslerinin ilk paragraflarında kaldığını ortaya çıkartmaktadır. Lakin şehir plancıları için bu süreç pes etme süreci değil, yeni hayatın domino taşlarını oluşturma ve çözümlerle salgın sonrası hayata bir an evvel uygulama kararları getirme sürecidir. Çünkü planlama akılcı ve problemler karşısında çözüm odaklı bir disiplindir. Uzun vadede geleceği planlar, tüm ihtimalleri düşünerek önce insana sonra kentine en uygun yaşam alanlarını sunmayı hedefler. Tarihten çıkarılan dersler ile bugün gelinen noktada çok daha güçlü bir bilim çağı vardır. 
$\mathrm{Bu}$ fırsatı değerlendirmek adına kentlerin daha sağlıklı ve gelecek için dirençli hale gelmesi şehir plancılarının ellerinde bulunmaktadır (Lai vd.,2020). Halk sağlı̆ıını; şehir planlaması, tasarım ve kamu politikasının merkezinde tutmak zorunlu olmalıdır. Ancak kültürel hafızanın en ufak bir parçası bir kez daha silinirse, geleceğin salgınları muhtemelen daha ölümcül olacaktır. Ve tarih bize bir şey öğretti ise, o da şu anki salgının son olmayacağıdır (Novakovic,2020).

Hemen herkesin dilinde söylediği gibi, ülkeler ve neredeyse tüm dünya bugün çok büyük bir sınavdan geçmektedir. Bu sınavın adı Covid-19. Eş zamanlı olarak bir sağlık krizi, sosyal kriz ve ekonomik kriz olan Covid-19, şehirlerin ne kadar iyi planlandığını ve yönetildiğini açığa çıkarmaktadır (Wahba ve Vapaavuori,2020). İnsan hayatını tehdit eden bu salgının içerisinde, sürece dahil iken hakkında kesin ve net konuşmalar yapmak hiçbir uzmanca kolay değildir. Etkilenen yaşam tarzlarına göre, yapılı çevrede dijital kanallara artan güven, pandemiden çok sonra da devam edebilir ve her yönü ile kentsel tasarımı etkileyebilir. Acil durumlarda alınan birçok önlem, günlük yaşamın, değişen alışkanlıkların ve davranışların bir parçası haline gelebilir, mimari ve şehir planlama yaklaşımlarına olumlu veya olumsuz bir müdahale olabilir (Megahed ve Ghoneim,2020). Planlama disiplini de bu küresel felaketin kentsel çapta yaygın bir kriz oluşturmasının ardından akademik yazıları kaleme almaya başladı. Fakat süreci henüz yaşarken kesin hüküm vermek sığ sonuçlar alınmasına neden olabilir. Ama elbette ki kentsel alanda değişimler yaşanmaya başlandığı sürece kent planlama alanında da değişimler yaşanacaktır. Şehir planlama ve sağlık kavramının bağlantı noktası 19.yy' dan bu yana süregelerek uzmanlaşma alanları oluşturmuştur. Belki de Covid-19 ile beraber sağlik perspektifi yeni yollarla planlamaya entegre edilebilecektir (Roses vd., 2020). Bu makale içerisinde kentsel planlama alanında yaşanması olası değişimler üzerine sürecin yeniliği ve sürerliği göz önünde bulundurularak, biraz daha genel ve sürekli yenilenmeye açı öneri ve fikirler getirilmektedir.

\section{Konuyla ilgili güncel yazın}

Makale araştırması; henüz yaşanmaya devam eden bir sürecin içerisinde iken yazıya dökülmeye başlanmıştır. Bu sebeple, bilgi ve verilerinin büyük çoğunluğunu bir kentli ve bir şehir plancısı olarak günden güne değişen tecrübelerinden sağlamaktadır. Akademik camiada tek tük kaleme alınmaya başlayan yazılar arasından şehir ve bölge planlama alanında hazırlanan ilk Türkçe yayın Covid-19 ve Şehirler üzerine olmuştur. Özuduru (2020) yayınında; kentlerin pandemi sürecinde mekansal ve sosyolojik olarak yaşayacağı değişimlerin sorgulamasını yapmaktadır. Yerel ekonomiler, iklimsel süreçler ve kentlerdeki sosyal sermayelerin değişimleri üzerine sorular sormaktadir.

Yabancı literatürde de salgın sonrası kentlerde yaşanacak dönüşümler üzerine akademik çalışmaların yayına girmeye başladığı görülmektedir. Bunlardan biri olan 17 farklı yazar tarafindan kaleme alınan The Impact of COVID-19 on Public Space: A Review of the Emerging Questions (COVID-19'un Kamusal Alan Üzerindeki Etkisi: Ortaya Çıkan Soruların Gözden Geçirilmesi) başlıklı makaledir. Makale her ülkenin farklı aşamalarda ve farklı yöntemler ile baş etmeye çalıştığı bir salgın sürecinde, kamusal alanlarda sosyal ilişkilerin ne şekilde etkileneceğine dair sorunları ele almaktadır. Bu sorunların şehir plancıları, mimarlar, kamu gözlemcileri vb. pek çok mesleki disiplinden uzmanlarca ele alınışını özetlemektedir.

Webster vd.,(2020)'nin hazırladıklar1 The nature of cities and the Covid-19 pandemic (Şehirlerin doğası ve Covid-19 salgını ) başlıklı makale ise; Covid-19 ile mücadele esnasında sağlıklı kalmak için bireylere önerilen sosyal mesafe, evde kalma ve okulları kapatma gibi politikaları kentsel yapılı çevreye uyarlamak adına bir takım yorumlar aktarmaktadır. Nüfus, iç mekanda kişi başına düşen belirli bir alanla sınırlandırıldıkça, mahallelerde inşa edilmiş çevrenin rolünün her zamankinden daha önemli hale geldiği savunulmaktadır. Özellikle zihinsel ve duygusal sağlığı korumak adına çevresel güçlendirmelerin önemi vurgulanmaktadır. 
Ahsan (2020)'In Strategic decisions on urban built environment to pandemics in Turkey: Lessons from COVID-19 (Türkiye'deki pandemilere kentsel yapılı çevreye ilişkin stratejik kararlar: COVID-19'dan dersler) başlıklı makalesi; Türk hükümetinin kentsel yapılı çevre perspektifi ile yeni normal döneme kadar aldığı kararları ve önlemleri sunmaktadır.

Matthew ve Mcdonald (2020)'1n hazırladıkları Cities under Siege: Urban Planning and the Threat of Infectious Disease(Hastalık Altındaki Şehirler: Kentsel Planlama ve Bulaşıcı Hastalık Tehdidi) makalesi; tarih boyunca doğal, kazara veya planlanmış şekilde oluşacak bulaşıcı hastalıklara karşı kentsel alanlarda hazırlıklı olmak gerektiğini savunmaktadır. Bu noktada plancıların krizler esnasında yönetimin orta noktasında yer alması, hazırlık yapması, tasarlayıp, bilgilendirmeler vermesi ve yardımda bulunması gereklidir denilmektedir.

Dietz vd.,(2020)'nin 2019 Novel Coronavirus (COVID-19) Pandemic: Built Environment Considerations To Reduce Transmission (2019 Yeni Koronavirüs (COVID-19) Salgını: Bulaşmayı Azaltmak İçin Yapılı Çevre Hususları) başılılı makalesinde; yapılı çevre karar vericilerine, bina inşa sürecindekilere ve çevresel olarak aracılık edilen yollarla bulaşıcı hastalık bulaşmasını en aza indirmeye çalışan tüm iç mekan sakinlerine uygulanabilir ve ulaşılabilir rehberlik sağlamak için Covid-19 hastalığını ve yapılı çevre etkisi sentezlenmektedir.

Slater vd.,(2020) Recommendations for Keeping Parks and Green Space Accessible for Mental and Physical Health During COVID-19 and Other Pandemics(COVID-19 ve Diğer Pandemiler Sırasında Parkları ve Yeşil Alanları Ruhsal ve Fiziksel Sağlık Açısından Erişilebilir Tutmaya Yönelik Öneriler) başlıklı makalesinde; salgın esnasında kapatılan park ve yeşil alanların fiziksel mesafeye dikkat etme koşulu ile tasarlanmasında kısa ve uzun vadede öneriler sunulmaktadır. Hem bedensel hem de zihinsel sağlığı korumak için park ve yeşil alanların önemine vurgu yapılmaktadır.

Megahed ve Ghoneim (2020) Covid-19 virüsüne karşı şehirlerin tasarlanıp planlamacılar ve mimarlarca yeniden inşa edilmesinin bir savunma olduğunu düşünmektedir. Antivirus-built environment: Lessons learned from Covid-19 pandemic (Antivirüs tabanlı ortam: Covid-19 salgınından alınan dersler) başlıklı makalelerinde de salgına karşı gerekli koruma sağlamak ve yapılı çevrede savunma sistemini güçlendirmek için tasarım fikirleri sunmakta ve geçmişte yaşanan salgınlardan edinilen derslerle ortaya çıkan kent planlama pratiklerini aktarmaktadır.

Lee vd., (2020)'nin Epidemic preparedness in urban settings: new challenges and opportunities (Kentsel ortamlarda salgına hazırlık: yeni zorluklar ve firsatlar) başlıklı makalesinde; ortaya çıkan bulaşıcı hastalıklara karşı kentsel ortamların korunmasının önemi ve kentsel ortamların özelliklerine göre salgın karşısında firsat ve zorlukları vurgulamaktadır.

Bunun dışında yabancı internet kaynaklarında forum biçiminde araştırma yazıları, pandemi boyunca sürekli değişerek devam eden süreç hakkında bilgiler aktarmaktadır. Halen yaşamaya devam ettiğimiz bu süreçte hem makalenin önerilerine destekleyici bir fikir hem de yazına kaynak sağlayan bir takım online çalışmalar da şehir plancıları ve mimarlar tarafindan yapılmıştır. $\mathrm{Bu}$ çalışmalardan biri sosyal medya platformu olan Instagram üzerinden yapılmıştır. Şehir Plancıları Odası Genel Merkezi yürütücülüğünde alanında uzman kişiler ile "Salgın Hastalıklar Ve Şehircilik" üzerine iki hafta süren konferanslar düzenlenmiştir (Şehir Plancıları Odası Genel Merkezi,2020). Ayrıca yine sosyal medya platformu olan You tube üzerinden Marmara Belediyeler Birliği tarafından düzenlenen Şehir Konuşmaları "Kentleri Dönüştüren Salgınlar" temalı online konuşma dizisi, 4 gün süren bir uzman görüşleri ortamı sunmuştur (Marmara Belediyeler Birliği,2020).

Araştırma çalışmasının oldukça yeni ve kısıtlı bir alan içinde oluştuğu bu dönemde literatür kullanımı genellikle yabancı kaynaklardan oluşmaktadır. Sürecin yeniliği gereği yalnızca güncel yazını derleyen bu bölümünde de özellikle değinilmek istenen nokta; pandemi süreci içerisinde hazırlanan veya sunulan herhangi bir çalışmanın literatüründe bile yeni bir düzende gerçekleşen 
çalışmalar ve ortamların varlığını sunmasıdır. Bundan sonraki akademik çalışmaların etkileneceği yeni bir düzen kurulması çokta uzak görülmemektedir.

\section{Covid-19'un Kentsel Etkilerine Kent Planlama Önerileri}

Televizyonlarda, gazetelerde, dergilerde sürekli tekrarlanmaya başlayan bir şey varsa o da artık hiçbir şeyin eskisi gibi olmayacağıdır. Çünkü neredeyse 4 aydır sosyal hayatlar eskisinden oldukça farklı bir işleyiş içerisine girmiştir. İnsanların son yıllarda sürekli beton binalar içerisinde, sanal bir dünyada, karşılıklı ilişkilerden uzaklaşarak yaşadığını söylerken aslında ne kadar da bu kentsel yaşamı istemedikleri görülmektedir. Parklar, sahiller, toplanma alanları belli kararlarla kapatılmıştır. Kentliler kendi kabuklarında, kendilerine yeterek yaşamayı öğrenmeye çalışmaya başlamıştır. Bu değişimler kentsel yaşamın, yaşamı oluşturan tüm unsurlarında olmuştur. Halkın sağlığ ve kentsel planlama birbirine bu noktada çakışmıştır. Çünkü kentler çok kalabalıklaşmıştır ve bu insan yoğunluğu salgının yayılmasının en büyük etkenidir. Dünya çapında yayınlanan Covid19 salgın haritalarında özellikle büyük metropol kentlerde oldukça belirgin ölçekte işaretlemelerle de bu durum en iyi şekilde açıklanmaktadır (Novakovic,2020). Böylelikle kentsel anlamda pek çok konu hakkında sorular oluşmaya başlamıştır. Bu sorular kentsel tasarım, bireylerin kentsel alan kullanımları, algıları ve davranışları gibi pek çok açıdan şekillenmektedir (Honey-Roses vd.,2020). $\mathrm{Bu}$ sebeple, aşağıda olası kentsel alan değişimleri sıralanmaktadır:

* Kentsel anlamda salgının yapacağı en büyük olası değişiklik nüfus yoğunluğu üzerinde olacaktır. Eğer bu hastalık ile yaşam öğrenmek durumunda kalınırsa, sosyal hayatı tehlikeye atmamanın ilk yolu kentsel alanlarda bırakılacak boşluklarla sağlanacaktır. Çünkü yapılan çalışmalar gösterdi ki yoğun nüfuslu bölgeler salgın riskine karşı daha savunmasizdir (Chang, 2020). Kent planlarında dikeyde veya yatayda fark etmeksizin yüksek yoğunluklu parsellerden kaçınan planlar ön plana çıkacaktır ki bu sadece pandemiye bağlı bir durum olarak değil, çevresel bağlamda da doğru planlanmış bir kent gerekliliğidir. Bu noktada yerel ihtiyaçlara yönelik perakende satış ve hizmetlerle canlı, ana caddeleri destekleyecek kadar yoğun, ancak çok katlı olmayan; bisiklet ve toplu taşıma altyapısını destekleyecek kadar yoğun, ancak metrolara ve büyük yer altı otoparklarına ihtiyaç duyacak kadar yoğun olmayan; bir topluluk duygusu oluşturmak için yeterince yoğun, ancak herkesin bireyselliğe kayması kadar yoğun olmayan alanlar yaratılmalıdır (Alter, 2020).

Kentsel boşlukların, açık alanların öneminin anlaşıldığı bu dönem içerisinde, evlerinde kalmaya çalışan her birey çok bunaldığı noktada kendini ilk olarak insandan ve yerleşimlerden uzak ormanlık alanlara atmaya başlamıştır. Fakat büyükşehirlerin, metropollerin ve ekonominin belkemiği olan bacalı ve bacasız sanayi kentlerinin ise orman alanları, milli parkları, açık alanları uzun sürelerdir tahrip ve ranta kurban olmuştur. Bu nedenle;

* Belki de ikinci en büyük olası şehir planlama adımı yerleşim alanlarında ve günübirlik yaşam merkezlerinin üzerinde yoğunlaşmaktan sıyrılıp doğa alanlarını, açık ve yeşil alanları kentsel planlarda en başa almak olacaktır. Her bir bireyin hareket ve gürültüden uzakta bir sığınma alanı veya spor yapma alanı olarak gördüğü yeşil alan ihtiyacının olacağ1 öngörülmektedir (Honey-Roses vd.,2020). Yoğun parsellerde konut ihtiyacını karşılamak adına köşe ada parçalarında konumlanan çocuk parkı ve yeşil alanları birbirinden ayrı düşünen uygulamalar yapılacaktır. Çünkü her yaşta birey için yeterli sayıda nefes alma alanına ihtiyaç vardır. Bu zamana kadar olması gereken metrekaresi kanunlarda kalmış kişi başına düşen yeşil alan miktarı, uygulamalarda oransal olarak yerini olabilecek en büyük rakamlarla almaya başlayacaktır. Zaten planlama disiplini uzun zamandır kentsel açık ve yeşil alanlar için bir mücadelenin içerisinde iken, salgınla beraber bu konu hakkında diğer kent aktörlerinden alacağı gücü uygulamalarda hemen kullanacaktır. Salgının odağı haline gelen yoğun yapılaşmış kentler için mevcutta çözümler plancılar öncülüğünde üretilecektir. Örnek olarak; yeşil alan miktarında artışı sağlamak adına kent içerisinde kullanılmayan boş alanların veya bina çatılarının değerlendirilmesi

Turkish Studies, 15(8) 
mümkündür (Honey-Roses vd.,2020).Ayrıca, kentsel doku içindeki geniş açık alanlar, şehirlerin acil durum hizmetlerini ve tahliye protokollerini uygulamasına yardımcı olabilecektir (Berg,2020).

Açık ve yeşil alanları kentlerde artıran projelerin hayata geçme aşamasında bireylerin evlerinde veya pandemi tedbirleri ile sosyal alanda geçirdikleri epey uzun bir dönem yaşanıyor olacaktır. Salgın tam anlamı ile kontrol altına alınsın veya alınmasın her iki durumda da ev hayatı üzerinde oldukça derin sorgulamalar yaşadığımız bir dönem yaşanmaktadır. Ev hayatı içerisinde bir bireyin yapması mümkün olan tüm eylemlerinin sorgulanmaya başlandığı bu sosyal uzaklaşma döneminde; apartman dairelerinin ve ana cadde üzeri binaların içerisinde bu pandemi sürecine kadar bireylerin sadece barınma ihtiyaçlarını karşılamak için yaşadığı fark edilmektedir. Hayatın akış1 yüzünden zaman ayrılamayacağı düşünülen bahçeli evlere özenilmekte, bugüne kadar soyutlayıcı görülen ve içerisinde yaşam alanı sunan kapalı sitelere karşı olumlu bakılmaya başlanmaktadır.

Covid-19 salgınının değiştirmesi muhtemel bir diğer büyük etkisi gayrimenkul talepleri üzerine olabilecektir. Talepleri hep kentsel ihtiyaç doğrultusunda gelişmiş kentliler, kentsel yaşamlarını değiştirmeye başladıkları bu dönemde önceliklerini de değiştirmek isteyeceklerdir. Eğitimin, iş hayatının eve taşındığı bu süreç, yaşanılan yeri seçerken bugüne kadar düşünülmemiş olan belirli bir takım şartları aramaya itecektir. Fakat unutulmamalıdır ki; insanlar geçmiş dönem salgınlarında da kentsel kalabalıklardan kaçarak kurdukları banliyölerde yaşarken, yıllar sonra çekici alanlar yine kent merkezilerinde kümelenmiștir. Bu durumda bugün kentsel alanlardan kaçınmaya çalıșan kesimin, belli zaman sonra tüm hayati imkanların daha geniş yer kapladığı merkezlere kayma düşüncesi belirebilecektir (Novakovic,2020).

Covid-19 salgını döneminde pek çok günlük iş ve işleyiş de evlerden yapılmaya başlanmıştır. Özellikle son dönemlerde teknolojinin de etkisi ile evlerden dijital platformlarda çalışma imkanı (home office) başta iş hayatları olmak üzere eğitim düzeylerinin hepsine entegre edilmiştir. Sürecin kontrolünde en başarılı adımlardan görülen eğitim alanlarından öğrencileri uzaklaştırmak, normalleşme döneminde de aynı kararla devam ettirilmektedir.

Eğitim ve iş alanları üzerinde kesin öngörmek zor olsa da muhtemel bir değişiklik ilerleyen dönemlerde mümkün olacaktır. Çünkü çoğu iş sektörü alana, binaya gereksinim duymadan da çalışmalar yapabildiğinin farkına varmıştır. Burada doğan iş gücü talebinin azalması durumu ise kritik bir eşik olduğu için bu dönüşümün varlığ da pek çok disiplinin değerlendirmesine açık gözükmektedir. Kentsel tasarım boyutunda görülen eksik ise; salgın dönemi ve sonraki dönemlerde çalışma alanlarını terk etmeden çalışan kesimin içerisinde kaldığı yap1 ve yapı alanları olabilir. Planlama alanında merkezi iş alanları (MİA), büyük katlı ofislerin bulunduğu toplu iş alanları son dönem planlarında oldukça yoğun görülmektedir. Burada çok katlı, bahçesiz ve yol-bina formu açısından ciddi ölçek sorunu yaşayan alanların varlığı tekrar gözden geçirilmelidir. Mimarı açıdan özellikle salgın sonrası normalleşme süreçlerinde camsız, balkonsuz veya havalanma alanı bulunmayan çok katlı binalar içerisinde sağlanan çalışma ortamları değişmezse, oldukça sağl1ksız ve tehlikeli olacaktır (Alter,2020). Bu öneriler sadece çalışan sağllğı için değil, aynı zamanda toplumsal sağlık açısından da gereklidir. Bugün resmi veya özel kurumlarda bahçelerinden taşan kuyruklarla işlemler yapılmaya çalışılmaktadır. Bu sosyal mesafeli bekleme süreci ne kadar devam edecek bilinmemekte, fakat bireyler bu şekilde yaşamayı öğrenecek ise özellikle kış mevsimleri için kurumsal alanların bahçelerine ve kent içerisinde konumlandırılmalarına yeniden düzenleme yapılması gerekecektir.

Buna karşı olarak; iş hayatını evden idare edebilen kesim dışında, çoğunlukla düşük gelirli büyük bir kesim iş için dışarıda olmak zorundadır. Yüksek gelirli kesim evinde izole çalışma imkanına sahipken, düşük gelirli kesim pandemi sürecinde de sokakta dolaşımına 
devam etme mecburiyetindedir. Bu noktada sosyal ve sınıfsal ayrımların güçlendirilmesine dayalı bir sonuç ortaya çıkaracağı da öngörülmektedir (Valentino-Devires vd,.2020). Bir kent sinıflar arası adil olmazsa güvenli de olmayacaktır (Alter,2020).

Eğitim alanları ise yeni bir dönüşümün varlığından söz etmek konusunda çelişkili olan donatı alanlarımızdandır. Çünkü Covid-19 salgının bulaşıcılığının özellikle gençler üzerinden güçlü taşındığı halk sağlığınca açıklandıktan sonra salgın döneminin dönüm noktalarından olan öğrencilerin evlerinden eğitimlerine devam etmesine karar verilmiştir. $\mathrm{Bu}$ salgın sürecinde verilen kararın salgın bitince devamlı hale gelebilmesi çok mümkün görünmemektedir. Bunun sebebi dijital platformlarda eğitimin yararları, getirdikleri ve götürdükleri konusu üzerinde tartış1ır olmasıdır. $\mathrm{Bu}$ konu hakkında uzmanlarca değerlendirme yapılması gerekir, fakat eğitim alanlarımızın planlanmasına dair kentsel ölçekte olmasa da bina ölçeğinde verilecek karar sürece göre şekillenebilir. Bunlar sınıfların yerleşim düzenleri, bahçe alanın sosyal mesafelere duyarlı olarak geniş tutulması ve kantin vb. sosyalleşme alanlarında yapılacak tasarımlar olabilecektir. Yine sınıf içerisinde camların kullanımı ve öğrencilerin kışın eğitim dönemi yaşamaları doğrultusunda binalara havalanma alanlarının eklenmesi eğitim kurumlarına yönelik düzenlemeler olabilecektir.

İşleyişi eve sığdıran veya sığdıramayan çoğu sektörün yanında topraktan kopamayan bir alan bulunmaktadır; o da tarım sektörüdür. 21. yy'ın terk ettiği veya uzaklaştığı bu alan özellikle salgının başından beri insanlığın temel ve en gerekli ihtiyacı olan gıdaya ulaşmanın zorunlu yoludur. Planlama alanında uzun sürelerdir tartışılan tarım alanlarının korunmasına, kırdan kente göçlerin aşırılığının önüne geçerek genç nüfusun tarımdan kopmamasına yönelik pek çok çalıştay yapılmaktadır. Tarım alanlarında ve tarımsal üretimde yaşanan iklimsel krizler, tahribatlar yönünden kentsel planlamanın sürekli tekrarladığı fakat gelişen çağda çözümleri hayata geçirtmekte zorlandığ 1 bir sektördür. Değerine, önemine ve insanlık var olduğu sürece hiç bitmeyeceğine dair fikirlerin yeniden gündeme geldiği tarım ve tarımsal üretim ile ilgili olarak bu salgın ile çıkardığımız derslerden kentsel alana öneriler yapılabilmektedir.

* Öncelikle tarımsal üretim kentsel veya bölgesel ölçekte korunması zorunlu ekonomik güçtür. Planlama alanlarında tarım alanının yeri her ölçekte özel önem arz eden alan olarak değerlendirmeye alınmalı ve sektörel büyüme adına geniş alanlarda tarımsal faaliyet kullanımları planlara işlenmelidir. İnsanların ekmek gibi gıdaları evlerinde yapmaya başlaması, balkonları olanların saksılarda maydanoz, biber, domates gibi sebzeler yetiştirmek istemesi sosyal yaşama yeni bir yön çizilebileceğini göstermiştir. Yine işgücü ve ekonomik durum nedeniyle kritik bir eşik olsa da kendi ekip biçtiğini yemeye karar veren bireyler oldukça fazla sayıda görülmektedir.

$\mathrm{Bu}$ oldukça küçük bir oranda olsa da tarım kentlerine bir dönüş yaşanması olasıdır. Salgın dönemi tatil anlayışında bile yoğunluklu şekilde büyükşehirlerden köylere ve kıra doğru bir talebin yaşandığ yıpratan hiçbir unsurun kıra getirilmemesidir. Yeniçağın olumsuz getirilerinden kaçmak için gidilen yerleri de bozmamak gereklidir. Fakat kent yaşamında temel erişimlere olan erişebilirliğin tarım kentlerinde de sağlanmasına böyle bir durumda gereklilik olacaktır (Berg,2020).

Kentler böylesi farklı bir düzene doğru ilerlerken karantina süreçlerinde boş kalan sokaklara, caddelere hayretle bakılmaktadır. Araba trafiğine, insan koşturmacasına olan alışkanlık sebebi ile salgınla mücadelede yasaklarla oluşan görüntü büyük bir boşluk sunmaktadır. Ulaşım talepleri bile değişmeye başlamıştır. Günümüz dünyasını hava kirliliğinden, karbon salınımından kurtarmak adına verilen mücadelede, toplu taşıma kullanımına olan yönlendirmeler bu salgın ile tepetaklak oldu denilebilmektedir. İnsanlar kendilerini diğer araçlara kıyasla daha hijyenik ve güvende hissettikleri özel araçlarına yüksek oranda artan bir taleple yönelmektedir. 
$\mathrm{Bu}$ durum kentsel planlama alanında sokak ölçeğinde ulaşım planlamasında bir takım değişimler yaşanabileceğini göstermektedir. İlk değişimin kaldırımlarla başlayacağ öngörülmektedir. Kent içi yaya hareketliliğinin fazla olduğu cadde ve sokaklarda kaldırım genişliğini bir o kadar büyük tutmak gerekecektir. Özellikle insan sağlığı açısından tavsiye edilen sosyal mesafenin korunması adına, kaldırımların genişletilmesi ve yaya geçitlerinin tekrar tasarlanması bir ihtiyaç olarak görülmektedir (Alter,2020). Yalnızca yayalar için değil, taşıtlar içinde kaldırım planlaması önem kazanmaktadır. Çünkü eve sipariş ve taşımacılık sektörünün teması azaltmak adına alınan tedbirli bir süreçte, yoğun talep edilir hale gelmesi bina önü teslimat aracı park yerleri ihtiyacını ortaya çıkartmaktadır. Bu da caddeye araç parkı konusunda yeni tasarımların önünü açacaktır (Honey-Roses, 2020).

Bazı kentlerde (Viyana, Boston gibi) yaya ve bisiklete alan sağlamak adına bu süreçte geçici yol kapatmaları gibi kısa vadeli önlemler alınmakta (Laker,2020) ve kentsel alanda böylesi projelerin uzun vadeye taşınması tartışılmaktadır (Bliss,2020). Ayrıca insanları hem bireysel olup hem de daha temiz bir ulaşım aracı olan bisiklete özendirmek adına bisiklet yollarında yapılacak yeni düzenlemeler mutlak suretle planlara işlenmelidir. Ulaşım planlamasının parçacıl çözüm üreten değil bütüncül çalışmalar yaratan bir alan olduğunu yeniden gündeme taşımak gerekecektir.

Kent içerisinde gelişenler dışında sosyal hayatlarda da yaşanan bazı tercihler söz konusudur. Kentsel hayatlar, sosyal hayatlar değişirken ekonomiye etkisi tartış1lır olsa da kente yönelik olumlu bir dönüşüm alışveriş anlayışında oldu denilebilmektedir. Kentlerin büyük kullanım alanlı, çevreye zararlı, trafik sorunu yaratan alışveriş merkezi alanlarına olan talebin azaldığı görülmektedir. Alışveriş merkezleri yerine açık alışveriş alanlarını tercih eden kullanıcı sayısı gözle görülebilir düzeylere ulaşmıştır. Planlamanın sık eleştirisine uğrayan bu toplu alışveriş alanları özellikle bina ölçeği açısından düzenlemelere gitmesi gerekli yerlerdir. Aynı zamanda bireylerin bir mekana gitmeden internet üzerinden alışveriş yapmaya yönelik taleplerinde de artış gözlemlenmektedir. Bu durum ileriki süreçlere taşındığında bina kullanımlarını azaltan, kentsel alanlarda yeni boşluklar yaratan bir durum oluştursa da pek çok sektörel kayba da sebebiyet verecektir (Honey-Roses vd.,2020).

Kapalı alışveriş yapılan alanlar yerine arasta veya açık alışveriş alanlarının çoğaltılması ve çarşı-pazar kültürünün yeniden canlandırılması hem sağlık açısından hem de küçük ölçekli ekonomilerde oldukça verimli olabilecektir. İnsanların tedirginlik duymadan tüketim yapabilmesi ekonomik açıdan da oldukça önemli yer tutmaktadır.

* Yine kafe, restaurant, sinema gibi toplu sosyal alanlarda henüz sürecin içerisindeyken başlayan fiziki anlamda değişimlerin bundan sonraki zamanlarda da değişmeye devam edecek mi noktasında çelişkiler bulunmaktadır. Bireylerin sık ve kalabalık toplandığı bu alanların fiziksel çözümlemeleri gerekecektir. Fakat bu değişim ne kadar süre devam edecek veya ekonomik anlamda (kısıtlı sayıda işleyen tesisler) nasıl dönüşler yaratacak konusunda da çalışmalar yapılmalıdır. Türkiye için bakıldığında, Akdeniz insanının sosyalleşmeyi seven yapısı sebebi ile sosyalleşme alanlarından uzaklaşma durumunu uzun vadeli görmemektedir.

Covid-19 sürecinde hastaların takibi ve salgının yayılımının önüne geçilmesi için temaslı takibi ve gözlemi için çeşitli uygulamalar hazırlanmıştır. Her ülke kendi akıllı sistemlerini kurmuştur (Honey-Roses,2020). Bu durum salgın sürecinin olumlu yönde yönetilmesini sağlamaktadır. Tüm bu Covid-19 değişimleri, dijital bağlantının ve siber güvenliğin merkezi yerini, insanların yaşadığı ve çalıştığı yerleşim alanlarının işlevlerini güçlendirmektedir. Ayrıca, şehirlerin genel vizyonlarını ve tasarımlarını göstermekte, yeniden tasarlanmaları gereken yolların altını çizmektedir (Muggah ve Ermacora,2020). Akıllı kent stratejilerinin ve planlarının 21.yy kentlerinde ve geleceğe yönelik kararlarında etkin bir rol üstleneceği öngörülmektedir. 
Daha dirençli kentler ile geleceğe hazırlanmak adına kentsel tasarımın, kentsel planlama ve kent yönetimde akıllı teknolojilerin entegrasyonu ve afet müdahale yaklaşımlarına ihtiyaç duyulmaktadır (Ahsan,2020). Kentsel ortamlarda daha iyi hazırlığın sağlanması, salgınlar ve diğer sağlıkla ilgili acil durumlarla başa çıkma kapasitelerinin güçlendirilmesine yeni bir vurgu yapılmasını gerektirecektir (Lee vd.,2020). Ayrıca şehir plancılarının salgın ve diğer tüm felaketlerin yönetimine entegre olması gerekmektedir. Böylece, bulaşıcı hastalıklar karşısında halkın savunmasız kalacağı noktalara planlama kararlarında hassasiyetle yaklaşılabilinecektir (Matthew ve McDonald, 2020).

\section{Sonuç}

Tüm bu verilen kentsel kullanım önerileri aslında planlama disiplininin mekana yönelik oluşturduğu çoğu standarttan farksızdır. Çok büyük değişimler veya hayata geçirilmesi mümkün olmayan öneriler değil, aksine olması gerekenin bir kez de halk sağlığı açısından gündeme gelmesini ifade etmektedir. Bu noktada yapılan her eleştiri ve verilen her öneri kent plancılarının veya yönetenlerinin ihtiyaçlarından değil, kentsel taleplerin varlığından ortaya çıkmaktır. Planlama hiçbir zaman zorunluluk veya kenti yönetme içgüdüsü ile uygulamalar yapmaz ve yapmamalıdır. Bu noktadan, yani Covid-19 salgın sürecinin henüz içerisindeyken bakıldığında; kentsel kullanım alanlarında büyüklü küçüklü değişimlere gidilebileceği görülebilmektedir. Salgın başından itibaren her ülke kendi yöntemini ve önlemini kentlisine göre almaktadır. Bu durumun geçiciliği veya kalıcılığı üzerine düşünürken pek çok yönden ele almak gerekmektedir. Çünkü atılan her adımda, ülkeleri sosyal ve ekonomik açılardan da ciddi şekilde etkileyecek sonuçlar söz konusu olmaktadır. Geçmiş salgınlardan dersler çıkarılmalı ve gelecek olası salgınlara dirençli kentler yaratmanın önemi vurgulanmalıdır. Kentlerde sürdürülebilir yaşam için yeni bir kalıp olarak sağlık temaları oluşturulmalıdır. Kentsel planlamanın standart kalıpları sağlık terimleri ile bağdaştırılmalıdır. Bunlar kentsel planlamanın bugün yaşanan süreç karşısında göstermesi gereken ilk değişim noktalarıdır. Fakat tüm bu değişimleri önce kent kullanıcıları belirleyecektir. Şehircilik veya kentsel planlama standartları değişir mi gibi yorumları yapmak için kullanıcı davranışlarını biraz daha uzun vadede görmekte yarar vardır.

Sonuçta; eğer kentlinin alışkanlıklarında bir dönüşüm yaşanacak olursa, planlama anlayışında da o noktadan itibaren değişimler yaşanacaktır. En önemli hedeflerinden biri sağliklı çevreler yaratmak olan bir disiplin içerisinde işleyiş gözlem ve sonuçlarla belirlenecektir. $\mathrm{Bu}$ dönem salgın içerisinde yaşananlar, kentsel karantina süreçlerinde yaşananlar ve normalleşme süreçlerinde yaşananlar yavaş yavaş kentsel anlamda da kendini göstermeye başlamaktadır. Özellikle insan davranışları her bir dönemde farklı farklı yönelimler göstermektedir. Fakat esas süreç, salgınla başa çıktığımız veya çıkamadığımız noktada başlayacaktır.

\section{Kaynakça}

Ahsan, M.M. (2020).Strategic decisions on urban built environment to pandemics in Turkey: Lessons from COVID-19. Journal of Urban Management,9(3),281-285. https://doi.org/10.1016/j.jum.2020.07.001

Alter, L.(2020,08 Nisan).Urban Design After the Coronavirus. Treehugger. https://www.treehugger.com/urban-design-after-coronavirus-4848013

Berg, R.(2020,10 Nisan).How Will COVID-19 Affect Urban Planning?.TheCityFix. https://thecityfix.com/blog/will-covid-19-affect-urban-planning-rogier-van-den-berg/

Bliss, L.(2020,03 Nisan). Mapping How Cities Are Reclaiming Street Space. Bloomberg Citylab. https://www.bloomberg.com/news/articles/2020-04-03/how-coronavirus-is-reshaping-citystreets 
Davies, A. (2020,13 Nisan). The pandemic could be an opportunity to remake cities. Wired. https://www.wired.com/story/pandemic-opportunity-remake-cities/

De-Vriees,J., Lu,D., \& Dans,G. (2020, April 03).Location Data Says It All: Staying at Home During Coronavirus Is a Luxury.The New York Times. https://www.nytimes.com/interactive/2020/04/03/us/coronavirus-stay-home-rich-poor.html

Dietz, L., Horve, P. F., Coil, D. A., Fretz,M., \& Eisen,J.A., Wymelenberg,K.V.(2020). 2019 Novel Coronavirus (COVID-19) Pandemic: Built Environment Considerations To Reduce Transmission. Msystem, (5)2. https://doi.org/10.1128/mSystems.00245-20

Ersoy, M. (2005). Türkiye'de Kent Planlamasının Güncel Sorunları. Ulusal Halk Să̆gl̆ğ Kongresi'nde sunulan bildiri, 137-144.

Honey-Roses, J., Anguelovski, I., Bohigas, J., Chireh, V., Daher, C., Konijnendijk, Litt, J., Mawani, V., McCall, M.,Orellana,A.,Oscilowicz,E.,Sánchez,U.,Senbel,M.,Tan,X., Villagomez,E.,Zapata,O.,Nieuwenhuijsen,M., (2020). The Impact of COVID-19 on Public Space: A Review of the Emerging Questions. https://doi.org/10.31219/osf.io/rf7xa

Klaus, I. (2020,06 Mart). Pandemics are also an urban planning problem. Citylab. https://www.citylab.com/design/2020/03/coronavirus-urban-planning-global-citiesinfectious-disease/607603/

Laker, L., (2020, 11 Nisan). World cities turn their streets over to walkers and cyclists. The Guardian. https://www.theguardian.com/world/2020/apr/11/world-cities-turn-their-streetsover-to-walkers-and-cyclists

Lee, V. J., Ho, M., Kai, C. W., Aguilera, X., Heymann, D. \& Wilder-Smith, A. (2020). Epidemic preparedness in urban settings: new challenges and opportunities. The Lancet Infectious Diseases, 20(5), 527-529. https://doi.org/10.1016/S1473-3099(20)30249-8

Lubell, S. (2020, 22 Nisan). Commentary: Past pandemics changed the design of cities. Six ways covid-19 could do the same. https://www.latimes.com/entertainment-arts/story/2020-0422/coronavirus-pandemics-architecture-urban-design

Markusen, A. (2020, 7 Nisan). Will COVID-19 drive us farther apart, or bring us together?. Minnesota reformer. https://minnesotareformer.com/2020/04/07/will-covid-19-virus-driveus-farther-apart-or-bring-u8s-together/

Marmara Belediyeler Birliği.(2020,Nisan 21).Şehir Konuşmalar [Video]. Youtube. https://www.youtube.com/playlist?list=PL6FT9NsPKXNF_au4ETIMzsRtfc0ChPzF

Matthew, R. A., \& McDonald, B. (2006). Cities under Siege: Urban Planning and the Threat of Infectious Disease. Journal of the American Planning Association, 72(1),109-117. https://doi.org/10.1080/01944360608976728

Megahed, N.A., \& Ghoneim, E.M.(2020). Antivirus-built environment: Lessons learned from Covid-19 pandemic. Sustainable Cities and Society,61,Makale 102350. https://doi.org/10.1016/j.scs.2020.102350

Muggah, R., Ermacora, T. (2020,20 Nisan). Opinion: Redesigning the COVID-19 city. NPR. https://www.npr.org/2020/04/20/839418905/opinion-redesigning-the-covid-19-city

Novakovic, S,.(2020,29 Mart) . Will COVID-19 spell the end of urban density? Don't bet on it. Azure. https://www.azuremagazine.com/article/will-covid-19-spell-the-end-of-urbandensity-dont-bet-on-it/

Slater, S.J., Christiana, R.W., Gustat, J.,(2020) Recommendations for Keeping Parks and Green Space Accessible for Mental and Physical Health During COVID-19 and Other Pandemics. 


$\begin{array}{llllll}\text { Preventing } & \text { Chronic } & \text { Disease } & \text { 2020, } & \text { 17, }\end{array}$
http://dx.doi.org/10.5888/pcd17.200204

Şehir Plancıları Odası.(2020). [@ spogenelmerkez]. (nd). [Instagram profili]. Instagram. https://www.instagram.com/spoistanbulsube/?hl=tr

Özüduru, H. (2020).Covid-19 ve Şehirler. İdealkent Yayınları.

Wahba, S., Vapaavuori, J.(2020,29 Nisan). A functional city's response to the COVID-19 pandemic. Sustainable Cities. https://blogs.worldbank.org/sustainablecities/functionalcitys-response-covid-19-pandemic

Webster C, V., Lai K., Kumari S., \& Sarkar C. (2020). The nature of cities and the Covid-19 pandemic. Science Direct. https://doi.org/10.1016/j.cosust.2020.08.008 